\title{
The subjective nature of creativity judgments
}

\author{
ALBERT N. KATZ and LORNE GIACOMMELLI \\ University of Western Ontario, London, Ontario N6A 5C2, Canada
}

\begin{abstract}
Typically, "creativity" has been studied by identifying highly creative individuals and then comparing them with a suitable comparison group. The objective techniques employed in the identification phase have depended either on the judgment of experts or on scores obtained on psychometric tests of creativity. The argument made here is that dependence on these approaches has blinded researchers to the fact that both approaches are based, ultimately, on subjective criteria and that little is known about the subjective theories of creativity held by people. The reported research is an initial attempt at tapping these subjective criteria. People $(N=80)$ sorted adjectives descriptive of problem solvers under a standard (sortfor-meaning) context or a context that indicated the sorting should be guided by their concept of "creative" problem solving. Hierarchical clustering analyses indicated that the adjectives were sorted to different meaning structures in the two contexts. It appears that a consensually shared notion of creativity is that it is postively related to heightened sensitivity to one's environment and a lessening of prejudicial thought.
\end{abstract}

Research into creativity has most typically employed a research design in which "highly creative" individuals are compared with a suitable comparison group. The highly creative group has usually been selected on the basis of either "expert" evaluators (e.g., MacKinnon, 1970 ) or tests that have been assumed to measure creativity levels (e.g., Bowers, 1979). While these operational definitions of creativity might appear to satisfy face validity, neither really addresses the criterion problem of the nature of creativity.

The first approach, that is, determining creativity by nomination of an expert panel, merely thrusts the definitional problem into the heads of experts without clarifying the basis upon which experts work. Taylor, Smith, and Ghiselin (1963) provide empirical evidence that different experts may even use different criteria. Taylor et al. obtained a large number of measures presumably relevant to the selection of creative research scientists. In general, the objective indexes (e.g., number of patents) did not correlate with subjective ratings. Of more immediate interest, however, is the relationship among the subjective ratings. Co-workers tended to select different people than did supervisors, who, in turn, differed from laboratory chiefs. It seems that not only is the criterion being thrust into the experts' heads, but also the tacit knowledge used in creativity selection may differ from one expert to the next.

Choosing creative individuals via objective tests appears to have an advantage over the use of experts, inasmuch as the criteria used to select the "highly creative" are made overt. Unfortunately, as Nicholls (1972) pointed out, the general failure of these tests to

This research was supported by Grant $410-78-0487$ to the senior author from the Social Sciences and Humanities Research Council of Canada. Requests for reprints should be sent to Albert N. Katz, Department of Psychology, University of Western Ontario, London, Ontario N6A 5C2, Canada. select people who also satisfy "expert" nomination indicates, at the least, that the criteria implicit in creativity tests and those used by experts differ. In recent years, a second problem has emerged. People instructed to "be creative" achieve higher creativity scores than they do when tested under standard instructional sets (Harrington, 1975; Ironson \& Davis, 1979; Katz \& Poag, 1979). Since the instructions are equivalent in all other ways, it appears that people, when merely told to act creatively, can alter their response patterns in ways that will then correspond to the implicit demands of the task. Creative performance thus appears to be not based on what people are constrained to do but on what they select to do. It should also be noted that most tests of creativity validate their measures by comparing their scores with the evaluations of peers or other knowledgeable "judges," albeit not of the expert level discussed earlier (e.g., Mednick, 1962; Torrance, 1974; Welsh, 1975). Thus, while the objective tests appear to have explicit criteria, they are nonetheless still based to a large extent on subjective criteria. Clearly, criteria defining the highly creative are thrust once again into the heads of observers.

The emphasis placed here on subjective criteria suggests that one aim of research into creativity should be to explicate these subjective criteria. The reported study is an initial attempt to use a relatively nonobtrusive technique to evaluate whether mention of the concept "creativity" automatically elicits a set of meaning structures that are not elicited when this concept is not mentioned. The logic of this study is similar to that employed in semantic priming studies in which the meaning of words is activated automatically. By varying the experimental context, one can determine whether relationships among the meaning of words can differ in different situations. In the present study, this will be done using a modified version of a technique used in 
psycholinguistic research (e.g., Fillenbaum \& Rapoport, 1971; Miller, 1969).

In this psycholinguistic tradition, participants are given a set of words representing a semantic domain (such as kinship terms) and are asked to sort these words into as many piles as they wish, with the words in each pile being those that share common meaning that is distinct from the meanings of the words in other piles. The assumption underlying this work is that the meaning of a lexical item is a function of the set of meaning relations that holds between that item and other items in the same domain (Fillenbaum \& Rapoport, 1971, p. 3). Hierarchical clustering techniques are then employed to uncover the underlying characteristics of the organization of the items, in a manner analogous to the use of factor analysis (i.e., to simplify into a set of more basic units).

In the present inquiry, the sorting task will proceed under either of two contexts. The first context will be the instructions typically given with this task and, as such, is relatively neutral with respect to creativity. Participants will be told to sort cards on the basis of similarity in meaning. The second context will tell participants that the words describe creative activity and ask them to sort words into piles that they feel represent similar notions of creativity. It is assumed that, relative to the first context, the sorting task performed under the second context will reflect the meaning structures unique to an individual's concept of creativity.

\section{METHOD}

\section{Participants}

Eighty undergraduate students at the University of Western Ontario served as participants. Half the participants were male (mean age $=22.8$ years, $S D=3.6$ years), and half were female (mean age $=22.6$ years, $\mathrm{SD}=4.8$ years).

\section{Stimuli}

The stimuli were 40 adjectives chosen from the Adjective Check List (Gough \& Heilburn, 1965). The following words were employed: alert, appreciative, appropriate, bizzare, complicated, conscientious, critical, curious, daring, eccentric, efficient, enterprising, enthusiastic, exceptional, flexible, foresighted, grotesque, honest, idealistic, imaginative, impulsive, ingenious, innovative, insightful, inspirational, intolerant, logical, methodical, persevering, realistic, rebellious, resourceful, sensitive, shrewd, spontaneous, surprising, unique, useful, versatile, and wise. The word "creative" was not chosen, inasmuch as it was felt that addition of this word would polarize judgment, thus masking differences among other closely related items.

A hierarchical procedure was used in selecting these items. First, several colleagues were asked to go through the checklist and pick those words that they considered descriptive of either problem solving contexts or problem solving processing. Only those words that were on more than one list were maintained. From this list, the author picked the final 40 words according to two criteria: (1) Only one item was used for which there were synonyms in the original Adjective Check List, and (2) a wide range of problem-relevant descriptors were maintained. card.

Each of the 40 adjectives was typed onto a separate file

\section{Procedure}

For each gender, participants were randomly assigned to one of the two instructional groups. Participants were tested individually. Subjects in the standard instruction group were told that the words described some aspects of problem solving (e.g., businessperson at a desk) and that they should sort the words into as many piles as they wished, with each pile representing words that they felt were similar in meaning.

The creative-salient instruction group received instructions that were as similar as possible to those described above. The major differences were those dictated by the emphasis that the participants' conception of creative activities were being assessed. That is, participants were told that the words described some aspects of creative activity (e.g., artist in a studio) and that each pile of sorted cards should represent words conveying a similar aspect of creativity. Once again, participants were encouraged to use as many piles as they wished.

\section{RESULTS AND DISCUSSION}

\section{Number of Piles Into Which the Cards Were Sorted}

Recall that participants were simply asked to sort the cards into as many different meaningful categories (or piles) as possible. This number was computed for each person. There was a tendency for fewer categories to be employed when creative-salient instructions were given (mean $=11.4, \mathrm{SD}=4.4$ ) compared to when standard instructions were given (mean $=14.6, \mathrm{SD}=6.8$ ). This difference was reliable $[\mathrm{F}(1,76)=5.35, \mathrm{p}=.02]$. It appears that when participants are told to sort cards describing creative activity, they synthesize or amalgamate the relevant conceptual categories compared with when they were asked to sort the exact same cards according to similarity in meaning.

\section{Hierarchical Clustering Analyses}

The data were combined into 40 by 40 adjective frequency matrices. A separate matrix was computed for the two instructional groups employed here. Each cell of a matrix consisted of the number of times, across participants, any two words had been placed in the same pile. This frequency matrix can be treated as representing meaning proximity; that is, two items with higher frequency counts can be considered as being closer in meaning then would be two items with lower conjoint frequency.

The connectedness method of hierarchical clustering analysis (see Fillenbaum \& Rapoport, 1971) was employed to uncover more basic meaning relationships. The results of these two analyses can be seen in Figures 1 and 2 . In these diagrams, the frequency at which adjectives joined a cluster is shown along the ordinate axis, the higher at which items join indicating a greater sharing of meaning, and the more central to the interpretation of the cluster. For instance, consider the group who sorted the words under creativity instructions. The first cluster is defined by the joining of the words "logical" and "methodical" at the highest level and, at somewhat lower levels, the words "efficient" and "realistic." To interpret this cluster, one must infer the commonality in meaning shared by these words. Given the nature of these words, I have described this cluster as representing systematicity in problem 


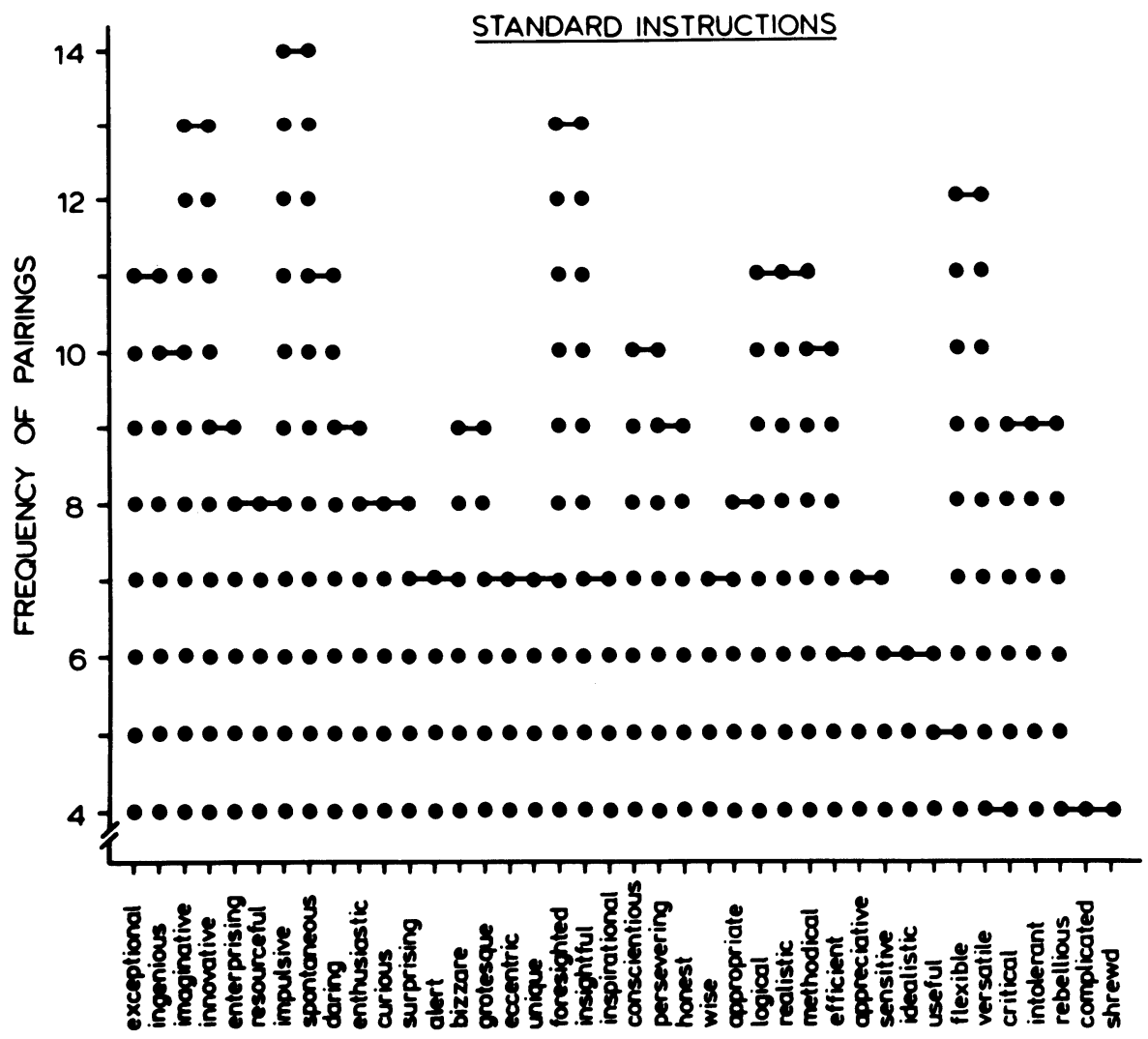

Figure 1. Hierarchical clustering of adjectives sorted under standard instructions.

solving. Examination across the two figures indicates five clusters of the same words in both instructional sets and one cluster in both sets that had some, but not all, words in common. These shared clusters tentatively have been labeled as: "clever" (items: imaginative, innovative, exceptional, ingenious), "hardworkingness" (conscientious, perservering, honest), "systematicity" (logical, realistic, methodical, efficient), "lack of rigidity" (flexible, versatile), and "wierdness" (bizzarre, grotesque). The one cluster somewhat similar between the two groups involves the common sorting of the words "impulsive" and "spontaneous." These two words appear as an isolated pair in the creative-salient instructional group and thus appear to connote something like "spontaneous activities." For the standard instructional group, however, "impulsive" and "spontaneous" was clustered with "daring" and "enthusiastic." This grouping seems to connote a more general concept of "adventureness."

Three additional clusters were isolated that were unique to one of the instructional groups. Two of these were found with the standard case. One of these appears to index a negative evaluative predisposition (the items "critical," "intolerant," "rebellious"). The second cluster consisted of the items "foresighted" and "insightful." It could be argued that both words represent an ability to make inferences based on partial information, and hence this concept might tentatively be labeled "inferential closure." Alternatively, the cluster may represent a sorting based not on meaning, but rather, on the physical similarity caused by the root "sight" common to both words. At present, we cannot distinguish between these possibilities.

The novel cluster found under creative-salient instructions consists of the items "appreciative" and "sensitive" and thus seems to represent something akin to the awareness of the characteristic of stimuli. Following the logic discussed earlier, it seems that activation of the concept "creativity" is associated with the arousal of a meaning structure for being aware and the inhibition of a conception involving negative evaluative predispositions. Thus, it seems that an important characteristic of peoples' subjective definitions of creativity involves a general openness to ideas, situations, and actions.

Presumably people who appear to approach problems with an open mind and without prejudice would be seen as being creative. This is not to say that these characteristics, by themselves, are sufficient to induce an observer to call someone creative or not. It may well be that such a judgment involves the conjunctive perception of "openness" with additional characteristics (e.g., some of the characteristics found under both conditions, such as being clever or showing a lack of rigidity). The point is that people appear to have a clear subjective conception of what constitutes a creative person that is separable from their conception of what is involved in noncreative intellectual performance. It seems reasonable, then, to assume that people evoke these unique conceptions when asked to rate people as being creative or not, or when instructed to "act creatively." One 


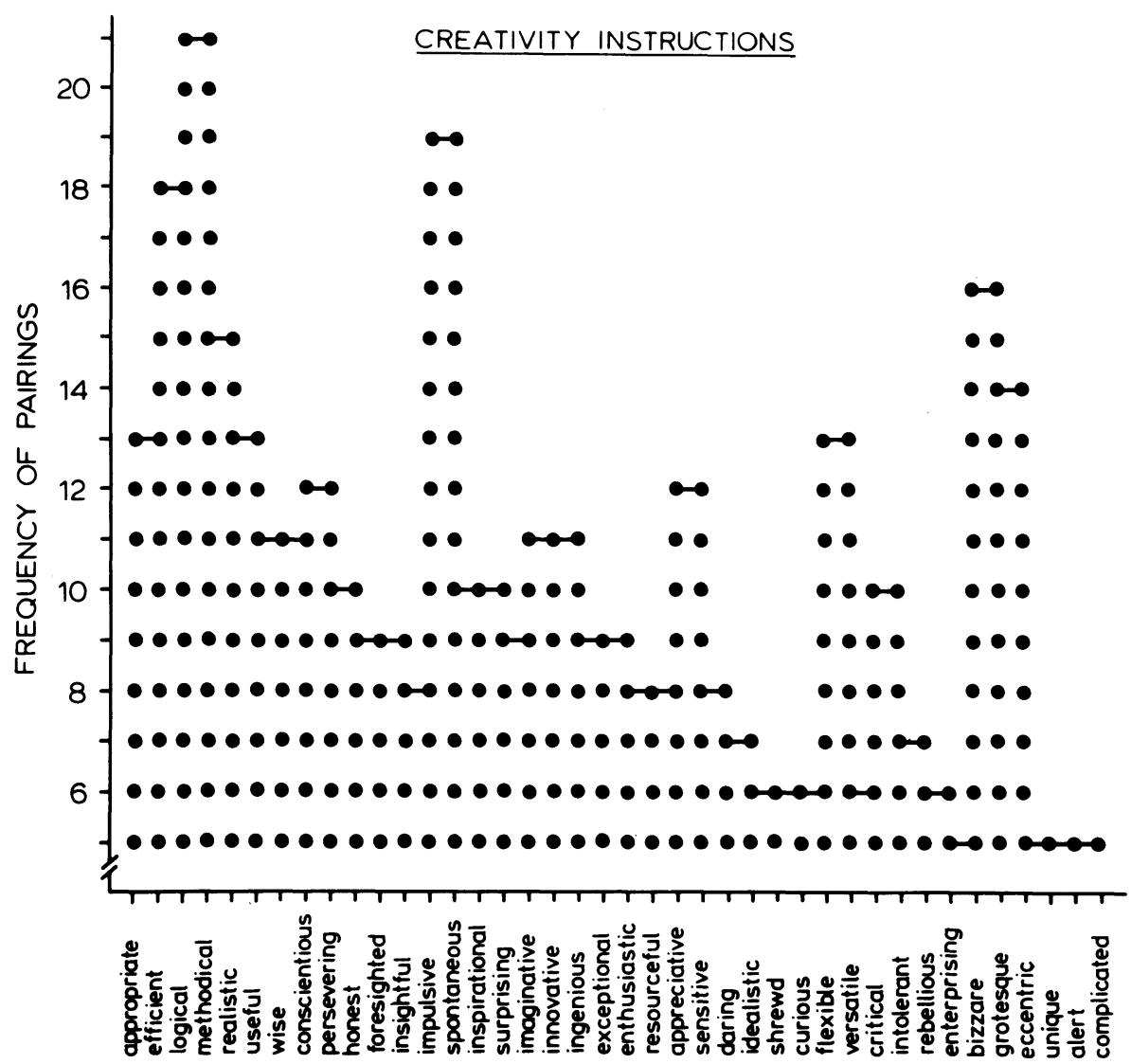

Figure 2. Hierarchical clustering of adjectives sorted under creative-salient instructions.

should note that such conceptions need not relate to actual performance criteria. To a large extent, we may see people as being creative according to how they act or present themselves and not according to what they produce.

Finally, it should be emphasized that the claim is not being made that only openness of mind is involved in the subjective consensual definition of creativity. As with all clustering techniques (including the more commonly used factor analysis), the clusters derived are only as good as the stimuli employed. The claim here is certainly not that all aspects of the meaning underlying creativity have been found, since additional clusters (or even some changes in clusters) might well occur if additional (or different) adjectives were sorted. This limitation, however, in no way negates the important finding observed here that people sort the exact same words (on the basis of meaning) differently under instructions that do and do not emphasize creativity. The favored explanation is that the instructions arouse different meaning structures. Presumably, instructions (or other environmental cues that arouse meaning) of the sort used here would be active when people make social judgments about who (or what) is creative.

\section{REFERENCES}

Bowers, P Hypnosis and creativity: The search for the missing link. Journal of Abnormal Psychology, 1979, 88, 564-672.
Fillenbaum, S., \& Rapoport, A. Structures in the subjective lexicon. New York: Academic Press, 1971.

Gough, H., \& Heilbrun, A. The adjective check list manual. Palo Alto, Calif: Consulting Psychologists Press, 1965.

Harrington, D. Effects of the explicit instructions to "be creative" on the psychological meaning of divergent thinking test scores. Journal of Personality, 1975, 43, 434-454.

Ironson, G., \& Davis, G. Faking high or low scores on the Adjective Check List. Journal of Creative Behavior, 1979, $13,139$.

Katz, A. N., \& Pona, J. Sex differences to "be creative" on divergent and nondivergent test scores. Journal of Personality, 1979, 47, 518-530.

MacKinnon, D. The personality correlates of creativity: A study of American architects. In P. E. Vernon (Ed.), Creativity. New York: Penguin Books, 1970.

MEDNICK, S. The associative basis of the creative process. Psychological Review, 1962, 69, 220-232.

Miller, G. A psychological method to investigate verbal concepts. Journal of Mathematical Psychology, 1969, 6, 169-191.

Nicholls, J. Creativity in the person who will never produce anything original and useful. American Psychologist, 1972, 27, 717-727.

Taylor, C., Smith, W., \& Ghiselin, B. The creative and other contributions of one sample of research scientists. In C. Taylor \& F. Barron (Eds.), Scientific creativity: Its recognition and development. New York: Wiley, 1963.

Torrence, P. Torrance tests of creative thinking: Norms technical manual. Lexington, Mass: Personnel Press, 1974.

WeLsh, G. Creativity and intelligence: $A$ personality approach. Chapel Hill: Institute for Research in Social Science, University of North Carolina, 1975.

(Received for publication May 7, 1982.) 